\title{
Lipid nanocapsules formulation and cellular activities evaluation of a promising anticancer agent: EAPB0503
}

\author{
Adrien Chouchou, Anne Aubert-Pouëssel ${ }^{1}$, Christophe Dorandeuํㄹ ${ }^{1}$ Zahraa Zghaib, Pierre Cuq, \\ Jean-Marie Devoisselle ${ }^{1}$, Pierre-Antoine Bonnet, Sylvie Bégu' ${ }^{1}$, Carine Deleuze-Masquefa \\ CNRS, ENSCM, IBMM, University of Montpellier, ${ }^{1}$ UMR 5253, CNRS, ENSCM, University of Montpellier, \\ Institut Charles Gerhardt Montpellier, Montpellier, France
}

\begin{abstract}
Objective: EAPB0503, lead compound of imiqualines, presented high antitumor activities but also a very low water solubility which was critical for further preclinical studies. To apply to EAPB0503, a robust and safe lipid formulation already used for poor soluble anticancer agents for injectable administration at a concentration higher than $1 \mathrm{mg} / \mathrm{mL}$.

Materials and Methods: Physicochemical properties of ЕAPB0503 were determined to consider an adapted formulation. In a second time, lipid nanocapsules (LNC) formulations based on the phase-inversion process were developed for EAPB0503 encapsulation. Then, EAPB0503 loaded-LNC were tested in vitro on different cell lines and compared to standard ЕАРB0503 solutions.

Results: Optimized EAPB0503 LNC displayed an average size of $111.7 \pm 0.9 \mathrm{~nm}$ and a low polydispersity index of $0.059 \pm 0.002$. The obtained loading efficiency was higher than $96 \%$ with a drug loading of $1.7 \mathrm{mg} / \mathrm{mL}$. A stability study showed stability during 4 weeks stored at $25^{\circ} \mathrm{C}$. In vitro results highlighted similar efficiencies between LNC and standard EAPB0503 solutions prepared in dimethyl sulfoxide.

Conclusion: In view of results obtained for loading efficiency and drug loading, the use of a LNC formulation is very interesting to permit the solubilization of a lipophilic drug and to improve its bioavailability. Preliminary tested pharmaceutical formulation applied to EAPB0503 significantly improved its water solubility and will be soon considered for future preclinical in vivo studies.
\end{abstract}

Keywords: Cancer chemotherapy, encapsulation, formulation, imiqualines, nanocapsules, solubility

Address for correspondence: Prof. Carine Deleuze-Masquefa, UFR Pharmacie, 15 Avenue Charles Flahault, 34000 Montpellier, France. E-mail: carine.masquefa@umontpellier.fr

\section{INTRODUCTION}

According to estimates from the International Agency for Research on Cancer, in 2012, there were 14.1 million new cancer cases and 8.2 million cancer deaths worldwide. ${ }^{[1]}$ The occurrence of cancer is increasing because of the growth and aging of the population, as well as an increasing prevalence of established risk factors such as smoking, overweight, and

\begin{tabular}{|l|l|}
\hline \multicolumn{2}{|c|}{ Access this article online } \\
\hline Quick Response Code: & Website: \\
\hline & www.jpionline.org \\
\cline { 2 - 3 } & \\
\hline
\end{tabular}

physical inactivity. The most commonly diagnosed cancers were lung (1.82 million), breast (1.67 million), and colorectal (1.36 million); the most common causes of cancer death were lung cancer (1.6 million deaths), liver cancer (745,000 deaths), and stomach cancer $\left(723,000\right.$ deaths). ${ }^{[2]} \mathrm{A}$ therapeutic arsenal is available for clinicians with alkylating agents, antimetabolites, antimicrotubule agents, topoisomerase inhibitors, or cytotoxic

This is an open access article distributed under the terms of the Creative Commons Attribution-NonCommercial-ShareAlike 3.0 License, which allows others to remix, tweak, and build upon the work non-commercially, as long as the author is credited and the new creations are licensed under the identical terms.

For reprints contact: reprints@medknow.com

How to cite this article: Chouchou A, Aubert-Pouëssel A, Dorandeu C, Zghaib Z, Cuq P, Devoisselle JM, et al. Lipid nanocapsules formulation and cellular activities evaluation of a promising anticancer agent: EAPB0503. Int J Pharma Investig 2017;7:155-63. 
antibiotics, but it presents some limitations with the failure of cure because of delivery problems (blood brain barrier) or of resistance. Then, the development of new drugs is required. We studied imidazo $[1,2-a]$ quinoxaline compounds, also called imiqualines (protected by a patent since 2008 and granted in the USA in February 2013). ${ }^{[3,4]}$ Heterocyclic systems containing the quinoxaline moiety exhibit high biological activities such as antitumor, antiviral, antibacterial, or anti-inflammatory. ${ }^{\left[{ }^{[}\right]}$Among the derivatives annulated at bond A, imidazoquinoxalines hold a special place since many active compounds have been developed ${ }^{[6]}$ and among them, EAPB0203 and EAPB0503 derivatives have been identified as lead compounds thanks to their in vitro activities against human melanoma cancer cell lines (A375, M4Be). ${ }^{[7]}$ These two compounds are characterized by a phenylethyl moiety for EAPB0203 and a methoxyphenyl moiety for EAPB0503 in position 1 of the heterocycle structure [Figure 1]. EAPB0503 has shown potent inhibition of the tubulin polymerization which is correlated to its antiproliferative activity ${ }^{[8]} \mathrm{EAPB} 0503$ is considered as a promising anticancer agent as it presents a 9-fold increase activity compared to EAPB0203, but it presents very high lipophilicity $(\log \mathrm{P}=4.48)$ which is critical for further preclinical studies.

For many years, the industrial development of new anticancer molecules often stopped because of (i) their poor selectivity responsible for major adverse effects and (ii) their poor water-solubility decreasing their bioavailability. ${ }^{[9,10]}$ To overcome these mains hurdles, nanomedicine was increasingly developed to improve the drug solubility and the targeting of cancer cells. In this context, liposome formulations are being marketed in several types of cancers with specialties such as Myocet ${ }^{\circledR}$ and Doxil ${ }^{\circledR}$ (doxorubicin) or Daunoxome ${ }^{\circledR}$ (daunorubicin). ${ }^{[11,12]}$ However, liposomes have significant drawbacks: Their manufacturing processes may require the use of solvents, their encapsulation rates

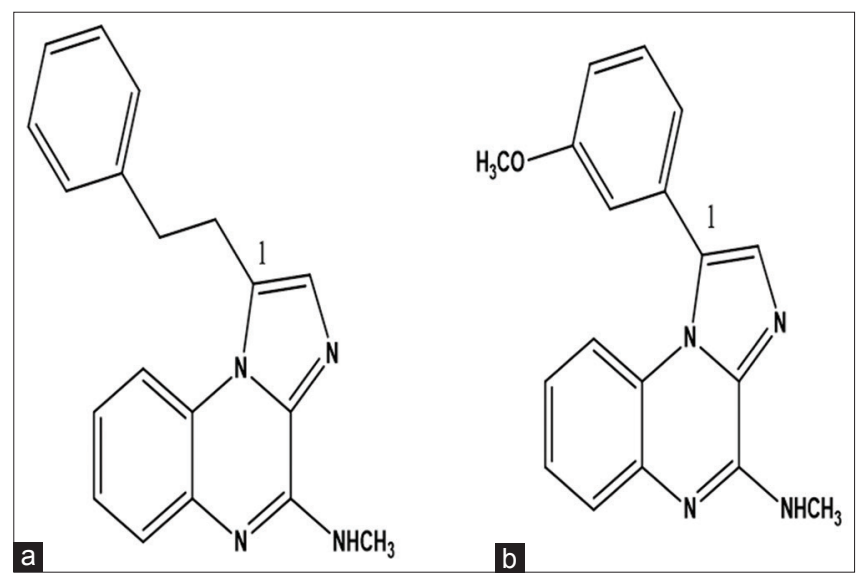

Figure 1: Chemical structures of imiqualines lead compounds: (a) EAPB0203 and (b) EAPB0503 are not optimal and their stability in biological fluids is insufficient. ${ }^{[13]}$ During the last 20 years, new drug carriers and called lipid nanoparticles (LNC) have been designed to overcome these drawbacks. ${ }^{[14]}$

Among them, LNC nanocarriers were developed by Heurtault et al. ${ }^{[15]}$ They are based on the phase-inversion process and are organized with an oily core surrounded by a membrane composed of mixture of lecithin and pegylated surfactant. ${ }^{[16]} \mathrm{LNC}$ formulation is interesting for multiple benefits: The use of pharmaceutical excipients approved for in vivo administration, ${ }^{[17]}$ the simplicity of the method which requires no organic solvents and provides high encapsulation efficiencies. ${ }^{[14]}$ Moreover, LNC represent the best compromise between stability in biological fluids, ability to encapsulate efficiently lipophilic drugs, and specific targeting of cancer cells. LNC present in vitro release profiles following zero-order kinetics with an almost complete release after $24 \mathrm{~h}$ at $37^{\circ} \mathrm{C} \cdot{ }^{[18]}$ This release profile associated with tumor accumulation due to the Enhanced Permeation and Retention (EPR) effect allow a significantly increase of the effectiveness of the encapsulated drugs while reducing side effects. ${ }^{[16]}$ Moreover, LNC are interesting nanocarriers also for their versatility; it would be possible to modify their surface with antibodies to improve targeting and then therapeutic efficiency. ${ }^{[19]}$ Moreover, such LNC showed reverse resistance against the P-glycoprotein, which is an important and the best-known membrane transporter involved in multidrug resistance. ${ }^{[20]}$ LNC have already been used to formulate anticancer agents with high lipophilicity, such as paclitaxel $(\log \mathrm{P}=3.2)$ and etoposide $(\log \mathrm{P}=0.73)$ to increase bioavailability for paclitaxel $^{[21]}$ or increase in vitro activity for etoposide. ${ }^{[22]}$ Hence, LNC appeared as a promising tool for EAPB0503 encapsulation both to dispose of an injectable formulation, to reach higher EAPB0503 intratumoral concentrations and to take advantages of EPR effect. ${ }^{[23]}$

In this article, physicochemical properties of EAPB0503 were first determined to consider an adapted formulation. In a second time, LNC formulations loaded with EAPB0503 were developed. Obtained LNC presented satisfying loading efficiencies and size distribution. Then, EAPB0503 loaded-LNC were tested in vitro on different cell lines and showed improved activities compared to standard EAPB0503 solutions in dimethyl sulfoxide (DMSO), highlighting their potential as candidates for anticancer therapies.

\section{MATERIALS AND METHODS}

\section{Chemicals and reagents}

EAPB0503 (1-[3-methoxyphenyl]-N-methylimidazo [1,2-a] quinoxalin-4-amine; molecular weight, $304 \mathrm{~g} / \mathrm{mol}$ ) was 
synthesized by the Pharmacochemistry and Biomolecules laboratory (IBMM Montpellier, France). ${ }^{[7]}$ This compound was stored at $20^{\circ} \mathrm{C}$ protected from light. Lipoïd ${ }^{\circledR}$ S75-3 (soybean lecithin at 70\% of phosphatidylcholine and $10 \%$ phosphatidylethanolamine) was obtained from Lipoïd Gmbh (Ludwigshafen, Germany). Kolliphor ${ }^{\circledR}$ HS 15 (mixture of free polyethylene glycol [PEG] 660 and PEG 660 hydrostearate) was a gift from BASF® (Ludwigshafen, Germany). Labrafac ${ }^{\circledR}$ WL 139 was obtained from Gattefossé (Saint-Priest, France). Purified water was obtained from a MilliQ ${ }^{\circledR}$ System (Millipore, Paris, France). Vegetable oils were obtained from Cooper (Melun, France) and were approved for pharmaceutical use. Salts and solvents high-performance liquid chromatography (HPLC) grade were purchased from Sigma-Aldrich (Saint-Louis, Missouri, USA). Neutral red, isopropyl alcohol, and hydrochloric acid were obtained from Merck (Darmstadt, Germany).

$\log \mathbb{P}$

The $\log \mathrm{P}$ values of $\mathrm{n}$-octanol/water were calculated by the commercially available computer programs ACDlabs software (ACD/Structure Elucidator, version 12.01, Advanced Chemistry Development, Inc., Toronto, ON, Canada, www.acdlabs.com, 2012).

\section{Physicochemical characterization of EAPB0503}

In addition to the analyses previously described (NMR, HR-MS, and elemental analysis), ${ }^{[7]}$ we conducted complementary analyses to accurately characterize the drug.

\section{Thermal analysis}

Differential scanning calorimetry (DSC) measurements and thermogravimetric analysis (TGA) were performed using a DSC 4000 standard single-furnace equipped with an intracooler and a STA6000 (Perkin-Elmer, Massachusetts, USA). DSC and TGA experiments were carried out under an inert atmosphere, with 2 bars nitrogen pressure. Samples were weighed $(5.0 \pm 0.5 \mathrm{mg})$ in standard $50 \mu \mathrm{L}$ aluminum sealed pan for DSC and in ceramic pan for TGA. To determine melting or crystallization temperatures of EAPB0503, DSC experiment was carried out from $0^{\circ} \mathrm{C}$ to $350^{\circ} \mathrm{C}$ and from $350^{\circ} \mathrm{C}$ to $0^{\circ} \mathrm{C}$ at a rate of $10^{\circ} \mathrm{C} / \mathrm{min}$. To determine the degradation temperature of EAPB0503, TGA was performed from $20^{\circ} \mathrm{C}$ to $350^{\circ} \mathrm{C}$ at a rate of $10^{\circ} \mathrm{C} / \mathrm{min}$.

\section{Solubility of EAPB0503 in oils and solvents}

First, a screening study was performed to select oils (pharmaceutical grade) able to solubilize EAPB0503. Labrafac ${ }^{\circledR}$ WL 139, castor, olive, soybean, and sesame oils were tested. $5 \mathrm{mg}$ of EAPB0503 was added in $1 \mathrm{~g}$ of oil, the samples were mixed with magnetic stirring during $24 \mathrm{~h}$ at $20^{\circ} \mathrm{C}$. Then, samples were observed to evaluate the solubility of EAPB0503. Second, the saturation solubility of EAPB0503 in solvents was determined by HPLC. ${ }^{[24,25]}$ Solvents were saturated with EAPB0503 and then centrifuged at $5000 \mathrm{~g}$ for 5 min using a Sigma 2k 25 ultracentrifuge (Sigma Zentrifugen, GmbH, Germany). The supernatant was assayed by HPLC with a LC62010HT (Shimadzu, Kyoto, Japan) using a C8 Zorbax ${ }^{\circledR}$ eclipse XDB (Extra-Dense Bonding) analytical column $(150 \mathrm{~mm} \times 4.6 \mathrm{~mm}, 5 \mu \mathrm{m}$, Agilent Technologies, Santa Clara, California, USA). Chromatographic conditions were optimized to improve sharp peak shape with adequate response. This included composition of the mobile phase, $\mathrm{pH}$ of buffer solution, flow rate, and also column type (C8, C18, or Shield RP18). Using the C18 or Shield RP18 column, analytes were too retained due to hydrophobic interactions. Best separations of the analytes and relative short analysis time were obtained on a C8 Zorbax eclipse $\mathrm{XDB}$ using a mobile phase consisting of acetonitrile and $2 \mathrm{mM}$ ammonium formate buffer $\mathrm{pH}=3(0.6 \mathrm{~mL} / \mathrm{min}$ during a run time of $12 \mathrm{~min})$. The column was maintained at $20^{\circ} \mathrm{C}$ and the autosampler temperature was $4^{\circ} \mathrm{C}$. The detection was carried by a UV lamp (UV-VIS detector, Shimadzu, Kyoto, Japan). The data acquisition was under the control of Analyst 1.5.2 Software. Standard EAPB0503 solutions prepared in DMSO within a range 50-1000 $\mu \mathrm{g} /$ $\mathrm{mL}$ were used for a calibration curve (calibration curve: $\mathrm{r}^{2}=0.998$ and $\%$ RSD is 2.5).

\section{Formulation of lipid nanocapsules}

$100 \mathrm{nmLNC}$ suspensionswere prepared according to Heurtault et al. process ${ }^{[15]}$ without EAPB0503 (called blank LNC) and loaded with EAPB0503 at low concentration (called LNC low) or at high concentration (called LNC high) [Table 1]. The proportions of each excipient (Labrafac ${ }^{\circledR}$ WL 139 as oil phase, Kolliphor ${ }^{\circledR}$ HS 15 and Lipoïd ${ }^{\circledR}$ S75-3 as surfactants) were chosen according to the tertiary diagrams published by Heurtault et al. ${ }^{[16]}$ and are approved by the FDA for parenteral administration. This formulation phase-inversion process is based on two steps. First, magnetic stirring

Table 1: Composition of lipid nanocapsules suspensions loaded (lipid nanocapsules low and lipid nanocapsules high) or not (blank lipid nanocapsules) in EAPB0503

\begin{tabular}{|c|c|c|c|}
\hline Formulation & Blank LNC & LNC low & LNC high \\
\hline Kolliphor $^{\circledR}$ HS 15 & $0.484 \mathrm{~g}$ & “ & “ \\
\hline Lipoïd $^{\circledR}$ S75-3 & $0.075 \mathrm{~g}$ & “ & “ \\
\hline Labrafac ${ }^{\circledR}$ WL 139 & $1.209 \mathrm{~g}$ & “ & “ \\
\hline $\mathrm{NaCl}$ & $0.089 \mathrm{~g}$ & “ & “ \\
\hline Purified water & $3.143 \mathrm{~g}$ & “ & “ \\
\hline Purified water $4^{\circ} \mathrm{C}$ & $7 g^{\circ}$ & “ & “ \\
\hline EAPB0503 & - & $0.014 \mathrm{~g}$ & $0.090 \mathrm{~g}$ \\
\hline
\end{tabular}

LNC: Lipid nanocapsules 
at $300 \mathrm{rpm}$ of all components was realized during four heating-cooling cycles (from $60^{\circ} \mathrm{C}$ to $90^{\circ} \mathrm{C}$ then a cooling from $90^{\circ} \mathrm{C}$ to $60^{\circ} \mathrm{C}$ at a rate of $4^{\circ} \mathrm{C} / \mathrm{min}$ ) using a hotplate digital stirrer. Magnetic agitation was kept at $300 \mathrm{rpm}$ during the whole process. The second step consisted on an irreversible shock induced by dilution with $7 \mathrm{~g}$ of purified cold water $\left(4^{\circ} \mathrm{C}\right)$ to the mixture at the transition phase. Finally, a slow magnetic stirring $(150 \mathrm{rpm})$ was applied to the suspension for $5 \mathrm{~min}$ at room temperature. In a final step, LNC suspensions were filtered using Minisart ${ }^{\circledR}$ syringe filters $0.2 \mu \mathrm{m}$ (Sartorius Stedim Biotech, Göttingen, Germany).

The phase inversion method reported by Heurtault et al. ${ }^{[16]}$ was modified for the preparation of LNC high suspension with the addition of chloroform $(5 \mathrm{~g})$ to increase EAPB0503 solubility. LNC high formulation enabled us to determine the maximum encapsulation capacity of nanocapsules. The chloroform was preferred to solubilize EAPB0503 because the heating cycles permitted its evaporation. Due to the possible presence of residual organic solvent, this formulation was not intended for pharmaceutical application and this reason was not be evaluated on cell lines.

\section{Characterization of lipid nanocapsules}

Size measurement and stability study

Size distribution, polydispersity index (PDI), and zeta potential measurements of LNC suspensions were determined by photon-correlation spectroscopy using a Zetasizer ${ }^{\circledR}$ Nano ZS (Malvern Instruments, Northampton, UK). $20 \mu \mathrm{L}$ of LNC suspension was diluted to $1000 \mu \mathrm{L}$ of purified water and added in disposable capillary cells (Malvern Instruments, Northampton, UK). Measurements were conducted in triplicate at $25^{\circ} \mathrm{C}$. The helium-neon laser operates at $663 \mathrm{~nm}$ with the scatter angle fixed at $173^{\circ}$. The autocorrelation function was modeled using the NonNegative Least Squares algorithm.

For the stability study, LNC low and blank LNC were divided into three groups immediately after preparation and stored at $4^{\circ} \mathrm{C}, 25^{\circ} \mathrm{C}$, and $37^{\circ} \mathrm{C}$. Samples were tested at day $0,7,14$, and 28 for size distribution and PDI measurements as described above.

\section{Determination of EAPB0503 loading and loading efficiency}

The EAPB0503 loading was carried out by HPLC (conditions previously described). In a first step, LNC were diluted in DMSO (by a factor 10) to solubilize all components, and then centrifuged at $5000 \mathrm{~g}$ for $5 \mathrm{~min}$ using a Sigma $2 \mathrm{k} 25$ ultracentrifuge (Sigma Zentrifugen, GmbH, Germany). The supernatant containing EAPB0503 solubilized in
DMSO was then assayed by HPLC. The loading efficiency was determined by dividing the experimental drug loading by the theoretical drug loading.

\section{Morphology by transmission electron microscopy}

Transmission electron microscopy (TEM) analysis was performed with a TEM Jeol 1200EXII (JEOL Ltd, Tokyo, Japan) with an accelerating voltage of $100 \mathrm{kV}$ and equipped with Quemesa Camera (Olympus, Japan). LNC suspensions were deposited on Formvar ${ }^{\circledR}$ copper TEM grids (Agar Scientific, Stansted, UK) and dried for $30 \mathrm{~min}$ at $25^{\circ} \mathrm{C}$.

\section{In vitro cytotoxic activity}

\section{Cell lines and culture techniques}

Human cancer cell lines (A375, MCF-7 and LS174T) were obtained from American Type Culture Collection (Rockville, Maryland, USA). A375 is a malignant melanoma cell line, MCF-7 is a metastatic breast cancer cell line, and LS174T is a malignant colon adenocarcinoma cell line. Cells were cultured in DMEM (Dulbecco's modified eagle media) medium supplemented with $10 \%$ heat-inactivated $\left(56^{\circ} \mathrm{C}\right)$ fetal bovine serum, $2 \mathrm{mM}$ L-glutamine, $100 \mathrm{IU} / \mathrm{mL}$ penicillin $\mathrm{G}$ sodium, and $100 \mu \mathrm{g} / \mathrm{mL}$ streptomycin sulfate (Gibco, Invitrogen, UK). Cells were maintained in a humidified atmosphere of $5 \% \mathrm{CO}_{2}$ in air at $37^{\circ} \mathrm{C}$.

\section{Cytotoxicity assay}

The neutral red viability test was carried out in optimized conditions (number of cells by well and the neutral red concentration). In all experiments, A375 MCF-7 and SL174T cells were seeded at a final concentration of 2500 cells/well in 96-well microliter plates and adhered overnight. At day 1, cells were exposed to negative vehicle controls (1\% DMSO/culture medium and culture medium alone), to positive control (EAPB0503 solution at 10-2 $\mathrm{M}$ in DMSO used from 2.5 to $5000 \mathrm{nM}$ ), and LNC low suspensions $(3.5-7000 \mathrm{nM})$. After $96 \mathrm{~h}$ of incubation, $100 \mu \mathrm{L}$ of neutral red solution in PBS $(15 \mu \mathrm{L} / \mathrm{mL}$, phosphate-buffer saline $\mathrm{pH} 7.3$ ) was added to each well, and the wells were incubated at $37^{\circ} \mathrm{C}$ for $3 \mathrm{~h}$. Then, the supernatant was carefully aspirated, and $100 \mu \mathrm{L}$ of a mixture of isopropyl alcohol and $1 \mathrm{M}$ hydrochloric acid $(96 / 4, \mathrm{v} / \mathrm{v})$ were added to each well. After $10 \mathrm{~min}$ of incubation and shaking, the optical density was measured at $570 \mathrm{~nm}$ in a microculture plate reader Dynatech MR 5000 (Dynex, Paris, France). For each assay, six experimental replications were performed in triplicate.

The individual cell line growth curves confirmed that all tumor lines in control medium remained in the log phase of cell growth $96 \mathrm{~h}$ after plating. Cell survival was expressed as percent of vehicle control. The $\mathrm{IC}_{50}$ 
values defined as the concentration of drug which produced $50 \%$ cell growth inhibition. About 50\% reduction of absorbance was estimated from the sigmoid dose-response curves.

\section{Statistics}

Results were expressed as mean values \pm standard deviation a Student's $t$-test was used for statistical comparison or analysis. $P<0.05$ was considered statistically significant.

\section{RESULTS}

\section{Physicochemical characterization of EAPB0503}

TGA analysis showed a degradation temperature of EAPB 0503 at $347^{\circ} \mathrm{C}$ (onset $210^{\circ} \mathrm{C}$ ) and the presence of linked water $\left(4 \%\right.$ weight loss $\left.150^{\circ} \mathrm{C}\right)$ (data not shown). Two endothermal melting peaks were observed in DSC at $147.27^{\circ} \mathrm{C} \pm 0.47$ and at $166.43^{\circ} \mathrm{C} \pm 0.40$ with a heat of fusion around 90 and $45 \mathrm{~J} / \mathrm{g}$, respectively. This reflected the presence of a mixture of two species, nevertheless, their proportion remains identical with reproducible thermograms whatever the sample (data not shown). It could be due to a hydrated form, confirmed by the presence of water in TGA. No crystallization peak was observed, despite an X-ray diffractogram showing numerous peaks (data not shown) meaning a crystalline solid. Therefore, EAPB0503 synthesis leads to reproducible batches and their thermal stability permits to ensure that EAPB0503 will not be degraded during LNC formulation process.

The solubility of EAPB0503 was determined in different oils at room temperature for a $5 \mathrm{mg} / \mathrm{mL}$ concentration as a biological efficient concentration. In vegetable oils (castor, olive, soybean, and sesame), the solubilization of the EAPB0503 was not complete; only the semi-synthetic oil Labrafac® WL 1349 allowed us to reach a $5 \mathrm{mg} / \mathrm{mL}$ concentration and even more $(12 \mathrm{mg} / \mathrm{mL})$. Then, the maximum concentration of EAPB0503 in the various studied solvents was determined by HPLC [Table 2], with an EAPB0503 retention time of $5.3 \mathrm{~min}$. The maximum concentration of EAPB0503 was observed in dimethylacetamide (DMA) $(24.8 \mathrm{mg} / \mathrm{mL})$ and in DMSO $(16.6 \mathrm{mg} / \mathrm{mL})$. DMSO is less viscous than DMA. Hence, DMSO was used for the determination of the drug loading and loading efficiency. The low water solubility of EAPB0503 was also confirmed with a maximum concentration of EAPB0503 in purified water $<0.1 \mathrm{mg} / \mathrm{mL}$.

\section{Characterization of lipid nanocapsules}

Size distribution and stability studies

Results presented in Table 3 showed blank LNC sizes centered around $100 \mathrm{~nm}(102.4 \pm 0.3, n=3)$ with a
Table 2: Solubility ( $\mathrm{mg} / \mathrm{mL}$ ) of EAPB0503 in different solvents performed by high-performance liquid chromatography (retention time $5.3 \mathrm{~min}$ )

\begin{tabular}{lc}
\hline Solvent & Maximum concentration $(\mathrm{mg} / \mathrm{mL})$ \\
\hline Dimethylacetamide & 24.8 \\
Dimethyl sulfoxide & 16.6 \\
Chloroform & 5.8 \\
Methanol & 0.7 \\
Absolute ethanol & 0.5 \\
Phosphate buffered saline & $<0.1$ \\
Purified water & $<0.1$ \\
\hline
\end{tabular}

Table 3: Lipid nanocapsules suspension characterizations: Size distribution ( $\mathrm{nm}$ ), polydispersity index, EAPB0503 loading $(\mathrm{mg} / \mathrm{mL})$, and loading efficiency (\%) of EAPB0503

\begin{tabular}{lccc}
\hline $\begin{array}{l}\text { LNC suspension } \\
\text { characterizations }\end{array}$ & $\begin{array}{c}\text { Blank LNC } \\
(n=3)\end{array}$ & $\begin{array}{c}\text { LNC low } \\
(n=3)\end{array}$ & $\begin{array}{c}\text { LNC high } \\
(n=1)\end{array}$ \\
\hline Size $(\mathrm{nm})$ & $102.4 \pm 0.3$ & $111.7 \pm 0.9$ & 116.5 \\
Polydispersity index & $0.044 \pm 0.003$ & $0.059 \pm 0.002$ & 0.048 \\
EAPB0503 loading $(\mathrm{mg} / \mathrm{mL})$ & - & $1.7 \pm 0.1$ & 8.2 \\
EAPB0503 loading efficiency (\%) & - & $96.7 \pm 2.1$ & 72.7 \\
\hline
\end{tabular}

LNC: Lipid nanocapsules

narrow distribution (PDI lower than 0.05). Loaded-LNC presented a slightly increased size at $111.7 \pm 0.9(n=3)$ and $116.5 \mathrm{~nm}(n=1)$ for low and high LNC, respectively. As a single peak was observed for loaded LNC samples, EAPB0503 was then localized into the nanocapsules. Due to the low water solubility, the amount of unencapsulated EAPB0503 has been eliminated during final filtration step. A stability study analyzing size measurements and PDI of blank LNC and LNC low was performed over a period of 28 days at $4^{\circ} \mathrm{C}, 25^{\circ} \mathrm{C}$, and $37^{\circ} \mathrm{C}$. The results of this study presented in Figure 2 highlighted the stability of the blank and loaded LNC with no modification neither of their size nor their PDI. LNC low were stable over the three temperatures for the tested period as particle size was $112.9 \pm 1.8 \mathrm{~nm}$ at day $28\left(37^{\circ} \mathrm{C}\right)$ compared to $111.7 \pm 0.92 \mathrm{~nm}$ at day $0(n=3)$. PDI remained inferior to 0.1 during the whole period, whatever the temperature. Moreover, for all formulations, the zeta potentials were around $-5 \mathrm{mV}$ (data not shown) as expected as LNC possess a neutral surface charge due to their PEG shell. ${ }^{[2]}$ The $\mathrm{pH}$ values were around 6 allowing us to consider intravenous or intraperitoneal routes of administration for in vivo studies (data not shown).

\section{Determination of loading efficiency and drug loading}

To achieve the drug loading and loading efficiency dosage of EAPB0503-loaded LNC, DMSO was used for its solubilizing properties. The loading efficiency of LNC low was satisfactory with around $97 \%$ of EAPB0503 entrapped into nanocapsules. For LNC high, the efficiency was lower around $73 \%$, but undeniably, LNC formulations allowed us to improve EAPB0503 solubility in aqueous system by a factor $17-82$. Indeed, solubility values have risen 
from $<0.1$ to $1.7 \mathrm{mg} / \mathrm{mL}$ and $8.2 \mathrm{mg} / \mathrm{mL}$ for LNC low and LNC high, respectively.

\section{Morphology by transmission electron microscopy}

TEM showed LNC presenting rounded shapes with a size distribution in accordance with the size measurements obtained by photon-correlation spectroscopy [Figure 3]. LNC were homogeneously dispersed without aggregate thanks to their shell of PEG chains.

\section{In vitro cytotoxic activity}

The neutral red viability test was used to determine in vitro cytotoxicity after exposure of LNC suspensions (loaded or not with EAPB0503). Results of in vitro tests on A375, MCF-7, and LS174T cancer cell lines showed similar efficiencies between LNC low and standard EAPB0503 solutions in DMSO. The cell survival profiles of the A375 cells, the MCF-7 cells, and the LS174T cells exposed on blank-LNC, LNC low and standard EAPB0503 solution were illustrated in Figure 4. $\mathrm{IC}_{50}$ values were, for LNC low and standard EAPB0503 solutions respectively, 192 $\mathrm{nM}$ and $230 \mathrm{nM}$ on A375 cell lines, $305 \mathrm{nM}$ and $217 \mathrm{nM}$ on MCF-7 cell lines and $931 \mathrm{nM}$ and $868 \mathrm{nM}$ on LS174T cell lines [Table 4]. Therefore, the cytotoxic activity of EAPB0503 was not modified by its encapsulation in LNC. A saline solution was tested with salt concentration equivalent to the LNC suspension, and no cytotoxic activity was found on tested cell lines. Similarly, blank LNC did not present cytotoxic activities on all tested cell lines $\left(\mathrm{IC}_{50}>10 \mu \mathrm{mol} / \mathrm{L}\right)$. Therefore, the cytotoxic activity found for LNC low formulation is due to compound EAPB0503 and not to the formulation or vehicle.

\section{DISCUSSION}

This study allowed us to formulate a poor soluble imiqualine in LNC for future intravenous administration. The potential of imiqualines as anticancer agent was already demonstrated in vitro with EAPB0203 compound. It can induce inhibition of cell proliferation, G2/M cell cycle arrest, and to initiate the apoptotic process via the intrinsic cell death pathway converging at the mitochondria. ${ }^{[27]}$ Its effect on resistant $\mathrm{T}$ lymphocytes was also highlighted. In the same way, we proved that EAPB0503 possessed more potent and induced a specific cell cycle arrest in mitosis in chronic myeloid leukemia cells and direct activation of apoptosis. ${ }^{[28]}$ Both compounds were able to impair A375 cell line growth, block cells in G2 and M phases, and induce cell death and apoptosis, with $\mathrm{IC}_{50}$ values of $0.2 \mu \mathrm{M}$ for EAPB0503 and $1.57 \mu \mathrm{M}$ for EAPB0203. ${ }^{[7]}$ This confirmed that EAPB0503 was more potent than EAPB0203, and it reinforced our will to promote this anticancer agent.

Concerning the therapeutic scheme, we previously showed that EAPB0203 $(20 \mathrm{mg} / \mathrm{kg}$ i.p., twice a week for 3 weeks followed by a second cycle after a wash-out of 15 days) had significant higher anti-tumor activity in

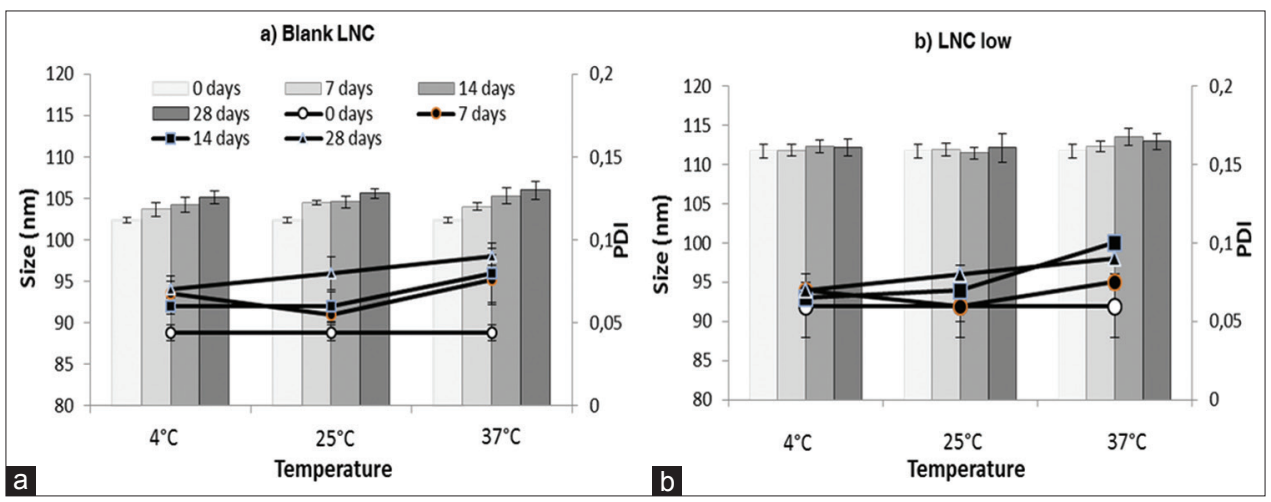

Figure 2: Stability study results of (a) lipid nanocapsules not loaded (blank lipid nanocapsules) and (b) lipid nanocapsules loaded in EAPB0503 (lipid nanocapsules low) over 4 weeks stored at $4^{\circ} \mathrm{C}, 25^{\circ} \mathrm{C}$ and $37^{\circ} \mathrm{C}(n=3)$. Stability is monitored with average particle size (columns) and Polydispersity Index $(\bigcirc, \boldsymbol{\square}$ and $\boldsymbol{\Delta})$ changes upon storage

Table 4: Concentrations of drugs which produced $50 \%$ cell growth inhibition (IC50) on A375, MCF-7 and LS174T cancer cell lines of EAPB0503 solution in dimethyl sulfoxide, lipid nanocapsules suspensions loaded (lipid nanocapsules low) or not (blank lipid nanocapsules) in EAPB0503 and saline solution. For each assay, six experimental replications were performed in triplicate

\begin{tabular}{lcccc}
\hline Cell lines & EAPB0503 $(\mathrm{nM})$ & LNC low $(\mathrm{nM})$ & Blank LNC $(\mu \mathrm{M})$ & Saline solution $(\mu \mathrm{M})$ \\
\hline A375 & $230 \pm 98.3$ & $192 \pm 19.3$ & $>10$ & $>10$ \\
MCF-7 & $217 \pm 20.0$ & $305 \pm 25.1$ & $>10$ & $>10$ \\
LS 174T & $868 \pm 323$ & $931 \pm 334$ & $>10$ & $>10$ \\
\hline
\end{tabular}

LNC: Lipid nanocapsules 
human melanoma (M4Be) xenografted nude mice than fotemustine (weekly intraperitoneal administration of $20 \mathrm{mg} / \mathrm{kg}$ for 3 weeks followed by a second cycle after a wash-out of 15 days). ${ }^{[2]}$ To achieve this experiment, EAPB0203, poorly soluble in water, was dissolved in a mixture intralipid/DMSO (50:50, v/v) at the concentration of $1 \mathrm{mg} / \mathrm{mL}$. This formulation allowed us to determine the minimal concentration to obtain the first results of in vivo activities. However, such a mixture of intralipid/DMSO presented drawbacks mainly because of the toxicity of DMSO, and an alternative formulation has to be developed with a required minimal concentration of $1 \mathrm{mg} / \mathrm{L} \cdot{ }^{[30]}$ Finally, the administration route had to be determined. Pharmacokinetics parameters investigated in rats, especially the bioavailability after intraperitoneal administration, which showed values of $22.7 \%$ for EAPB0203 and 35\% for EAPB0503. ${ }^{[31]}$ Consequently, to increase the in vivo

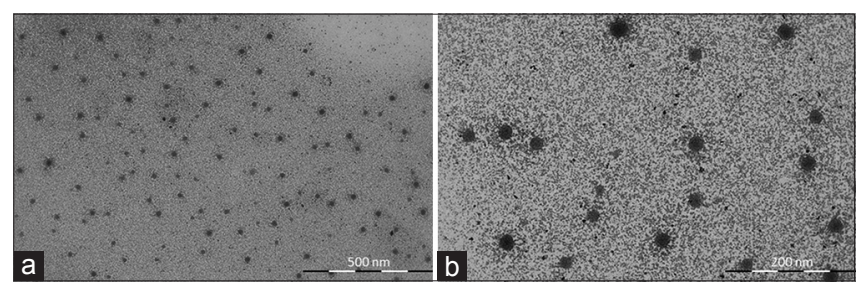

Figure 3: Transmission electron microscopy performed on lipid nanocapsules low suspensions left to dry for $30 \mathrm{~min}$ at $25^{\circ} \mathrm{C}$ after being deposited on Formvar ${ }^{\circledR}$ copper transmission electron microscopy grids activities of compounds, intravenous administration has to be considered.

The global results obtained on EAPB0203 and EAPB0503 permitted to identify EAPB0503 as a new lead compound of imiqualines derivatives. The evolution of chemical structure between EAPB0203 and EAPB0503 did not allow to decrease the lipophilic property $(\log P: 4.60$ and 4.48 , respectively). Consequently, the water solubility was not sufficient to use a classical formulation for intravenous administration.

The preliminary formulation tests considered the EAPB0503 solubility in oils. In various vegetable oils (castor, olive, soybean, and sesame oils), solubilities were not sufficient to obtain solutions with concentrations higher than $1 \mathrm{mg} / \mathrm{mL}$. On the other side, EAPB0503 showed a satisfactory solubility in Labrafac ${ }^{\circledR}$ WL 139 (higher than $12 \mathrm{mg} / \mathrm{g}$ ). Emulsion-based formulations were tested, but obtaining stable and micrometric sized emulsions required high energy processes and high levels of surfactants with potential toxicity. ${ }^{[32]}$ Thus, we considered a nanoencapsulation strategy and the formulation of EAPB0503-loaded LNC as injectable delivery systems. Different hydrophobic anticancer drugs have been encapsulated by this process. For example, etoposide, which water solubility is $0.978 \mathrm{mg} / \mathrm{mL}$, was formulated in

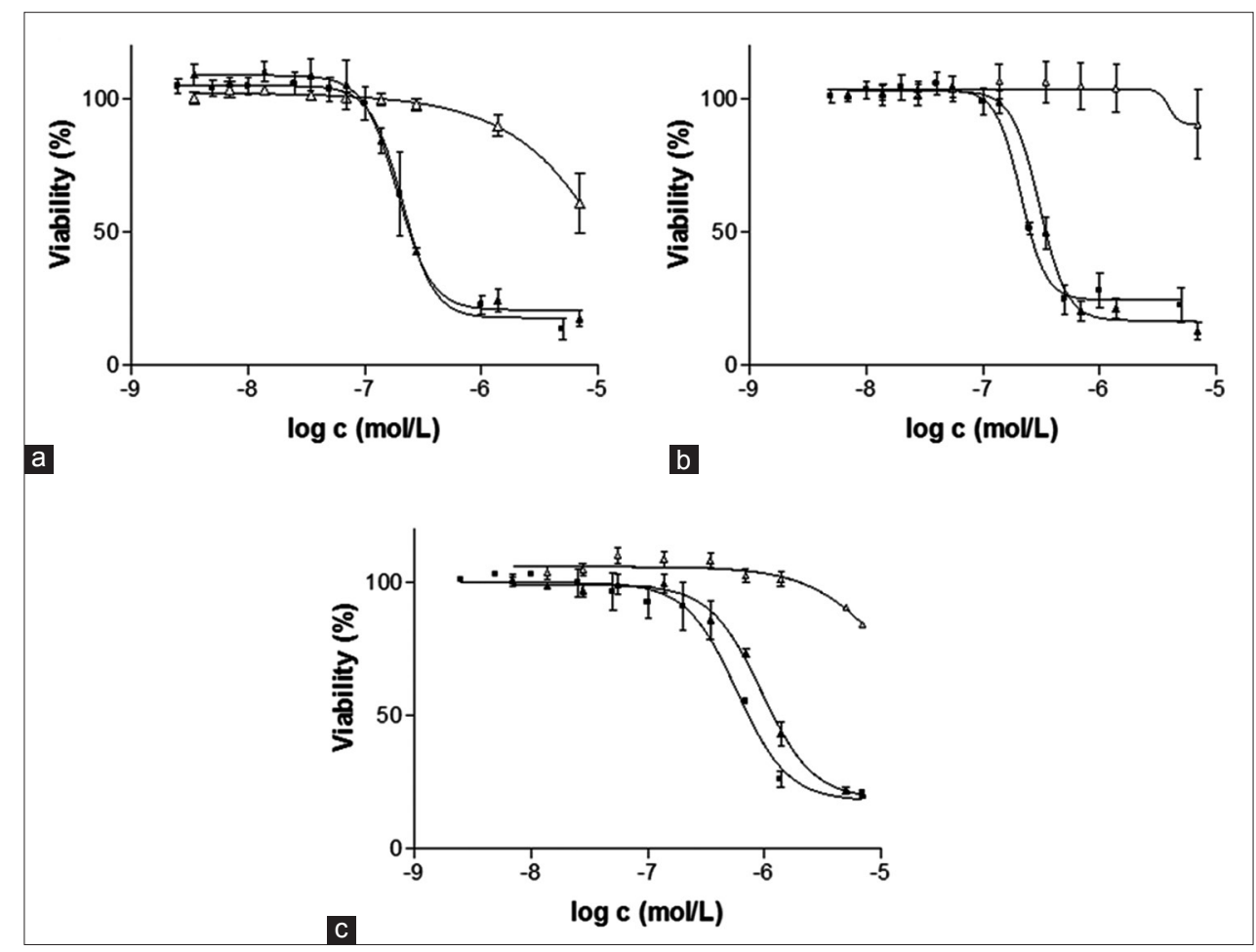

Figure 4: Cell viability assay on A375 (a), MCF-7 (b) and LS174T (c) cell lines after 72h relatively to the concentration of EAPB0503 loaded (lipid nanocapsules low: $\boldsymbol{\Delta}$ ) or not (blanck lipid nanocapsules: $\triangle$ ) in lipid nanocapsules or in standard EAPB0503 solution in dimethyl sulfoxide ( $\mathbf{\square})$. For each assay, six experimental replications were performed in triplicate 
LNC with a drug loading of $6.5 \pm 3.0 \mathrm{mg} / \mathrm{g}$ and a drug efficiency of $56.7 \pm 21.3 \%{ }^{[19]}$ More hydrophobic drugs such as docetaxel and paclitaxel (with a water solubility of $0.0127 \mathrm{mg} / \mathrm{mL}$ and $0.00556 \mathrm{mg} / \mathrm{mL}$, respectively) were also encapsulated with drug efficiency around $67 \%-90 \%$ and $95 \%-96 \% \%^{[18,33]}$ leading to drug loadings of $2 \mathrm{mg} / \mathrm{mL}$ and $4 \mathrm{mg} / \mathrm{mL}$, respectively. In addition to their solubilizing properties, LNC offer the size control via their composition. ${ }^{[34]}$ We chose the optimal formulation to obtain EAPB0503-loaded LNC with an average size of $100 \mathrm{~nm}$ and a PDI lower than 0.1 compatible with an injectable administration. Hence, homogeneous and stable $111.7 \pm 0.9 \mathrm{~nm} \mathrm{LNC}$ were obtained. On further optimization with drug loading, formulation with EAPB0503 at high concentration was developed. The drug loading was hence increased by $>4$ (from 1.7 to $8.2 \mathrm{mg} / \mathrm{mL}$ ) in comparison to LNC low. However, the drawback of this formulation is the use of chloroform, which is non-generally recognized as safe component and class 2 solvent ${ }^{[35]}$ to solubilize the drug. So for this reason, the second formulation has not been used in the cytotoxic assays but permitted us to know the loading capacity of the LNC.

The determination of in vitro cytotoxicity on three different cancer cell lines (A375, MCF-7, and LS174T) showed similar efficiencies for LNC low and standard EAPB0503 solutions in DMSO. Moreover, blank LNC did not show cytotoxic activities on all tested cell lines. These results, retention of activity for $\mathrm{LNC}$ low and nontoxicity for blank LNC, validate the use of LNC formulation to evaluate the activity of the drug. Therefore, encapsulation of EAPB0503 in LNC has not modified its cytotoxic activity.

Considering these results, the use of LNC for the formulation of the anticancer agent lipophilic EAPB0503 was relevant for its future development.

\section{CONCLUSION}

Results of this study led us to identify a pharmaceutical formulation to improve water solubility of EAPB0503: Lipid nanocapsules prepared with a simple process with safe components. This EAPB0503 formulation will be soon considered for future preclinical in vivo studies.

\section{Financial support and sponsorship}

Nil.

\section{Conflicts of interest}

There are no conflicts of interest.

\section{REFERENCES}

1. Torre LA, Bray F, Siegel RL, Ferlay J, Lortet-Tieulent J, Jemal A, et al. Global cancer statistics, 2012. CA Cancer J Clin 2015;65:87-108.

2. Ferlay J, Soerjomataram I, Dikshit R, Eser S, Mathers C, Rebelo M, et al. Cancer incidence and mortality worldwide: Sources, methods and major patterns in GLOBOCAN 2012. Int J Cancer 2015;136:E359-86.

3. Deleuze-Masquefa C, Moarbess G, Bonnet PA, Pinguet F, Bazarbachi A, Bressolle F. Imidazo[1,2-a]quinoxalines and derivatives for the treatment of cancers, Patent WO2009043934 A1; 2009.

4. Deleuze-Masquefa C, Moarbess G, Bonnet PA, Pinguet F, Bazarbachi A, Bressolle F. Imidazo[1,2-a]quinoxalines and derivatives for the treatment of cancers. Patent US 20138378098 B2; 2013.

5. Pereira JA, Pessoa AM, Cordeiro MN, Fernandes R, Prudêncio C, Noronha JP, et al. Quinoxaline, its derivatives and applications: A state of the art review. Eur J Med Chem 2015;97:664-72.

6. Mamedov VA, Kalinin AA. Advances in the synthesis of imidazo[1,5-a]- and imidazo[1,2-a] quinoxalines. Russ Chem Rev 2014:83:820.

7. Deleuze-Masquefa C, Moarbess G, Khier S, David N, Gayraud-Paniagua S, Bressolle F, et al. New imidazo[1,2-a] quinoxaline derivatives: Synthesis and in vitro activity against human melanoma. Eur J Med Chem 2009;44:3406-11.

8. Zghaib Z, Guichou JF, Vappiani J, Bec N, Hadj-Kaddour K, Vincent LA, et al. New imidazoquinoxaline derivatives: Synthesis, biological evaluation on melanoma, effect on tubulin polymerization and structure-activity relationships. Bioorg Med Chem 2016;24:2433-40.

9. Tafuri G, Stolk P, Trotta F, Putzeist M, Leufkens HG, Laing RO, et al. How do the EMA and FDA decide which anticancer drugs make it to the market? A comparative qualitative study on decision makers' views. Ann Oncol 2014;25:265-9.

10. Marchal S, El Hor A, Millard M, Gillon V, Bezdetnaya L. Anticancer drug delivery: An update on clinically applied nanotherapeutics. Drugs 2015;75:1601-11.

11. Szebeni J, Fülöp T, Dézsi L, Metselaar B, Storm G. Liposomal doxorubicin: The good, the bad and the not-so-ugly. J Drug Target 2016;24:765-7.

12. Latagliata R, Breccia M, Fazi P, Iacobelli S, Martinelli G, Di Raimondo F, et al. Liposomal daunorubicin versus standard daunorubicin: Long term follow-up of the GIMEMA GSI 103 AMLE randomized trial in patients older than 60 years with acute myelogenous leukaemia. $\mathrm{Br}$ J Haematol 2008;143:681-9.

13. Akbarzadeh A, Rezaei-Sadabady R, Davaran S, Joo SW, Zarghami N, Hanifehpour Y, et al. Liposome: Classification, preparation, and applications. Nanoscale Res Lett 2013;8:102.

14. Battaglia L, Gallarate M. Lipid nanoparticles: State of the art, new preparation methods and challenges in drug delivery. Expert Opin Drug Deliv 2012;9:497-508.

15. Heurtault B, Saulnier P, Benoit JP, Proust JE, Pech B, Richard J. Lipid Nanocapsules, Preparation Method and Use as Medicine, WO2001064328 A1; 2001.

16. Heurtault B, Saulnier P, Pech B, Proust JE, Benoit JP. A novel phase inversion-based process for the preparation of lipid nanocarriers. Pharm Res 2002;19:875-80.

17. Strickley RG. Solubilizing excipients in oral and injectable formulations. Pharm Res 2004;21:201-30.

18. Abdel-Mottaleb MM, Neumann D, Lamprecht A. In vitro drug release mechanism from lipid nanocapsules (LNC). Int J Pharm 2010;390:208-13

19. Béduneau A, Saulnier P, Hindré F, Clavreul A, Leroux JC, Benoit JP, et al. Design of targeted lipid nanocapsules by conjugation of whole antibodies and antibody fab' fragments. Biomaterials 2007;28:4978-90.

20. Garcion E, Lamprecht A, Heurtault B, Paillard A, Aubert-Pouessel A, Denizot B, et al. A new generation of anticancer, drug-loaded, colloidal vectors reverses multidrug resistance in glioma and reduces tumor 
progression in rats. Mol Cancer Ther 2006;5:1710-22.

21. Groo AC, Bossiere M, Trichard L, Legras P, Benoit JP, Lagarce F, et al. In vivo evaluation of paclitaxel-loaded lipid nanocapsules after intravenous and oral administration on resistant tumor. Nanomedicine (Lond) 2015;10:589-601.

22. Saliou B, Thomas O, Lautram N, Clavreul A, Hureaux J, Urban T, et al. Development and in vitro evaluation of a novel lipid nanocapsule formulation of etoposide. Eur J Pharm Sci 2013;50:172-80.

23. Huynh NT, Roger E, Lautram N, Benoit JP, Passirani C. The rise and rise of stealth nanocarriers for cancer therapy: Passive versus active targeting. Nanomedicine (Lond) 2010;5:1415-33.

24. Khier S, Moarbess G, Deleuze-Masquefa C, Solassol I, Margout D, Pinguet $\mathrm{F}$, et al. Quantitation of imidazo[1,2-a] quinoxaline derivatives in human and rat plasma using LC/ESI-MS. J Sep Sci 2009;32:1363-73.

25. Lafaille F, Solassol I, Enjalbal C, Bertrand B, Doulain PE, Vappiani J, et al. Structural characterization of in vitro metabolites of the new anticancer agent EAPB0503 by liquid chromatography-tandem mass spectrometry. J Pharm Biomed Anal 2014;88:429-40.

26. Vonarbourg A, Saulnier P, Passirani C, Benoit JP. Electrokinetic properties of noncharged lipid nanocapsules: Influence of the dipolar distribution at the interface. Electrophoresis 2005;26:2066-75.

27. Moarbess G, El-Hajj H, Kfoury Y, El-Sabban ME, Lepelletier Y, Hermine O, et al. EAPB0203, a member of the imidazoquinoxaline family, inhibits growth and induces caspase-dependent apoptosis in T-cell lymphomas and HTLV-I-associated adult T-cell leukemia/ lymphoma. Blood 2008;111:3770-7.

28. Saliba J, Deleuze-Masquéfa C, Iskandarani A, El Eit R, Hmadi R, Mahon FX, et al. EAPB0503, a novel imidazoquinoxaline derivative, inhibits growth and induces apoptosis in chronic myeloid leukemia cells. Anticancer Drugs 2014;25:624-32.

29. Moarbess G, Deleuze-Masquefa C, Bonnard V, Gayraud-Paniagua S, Vidal JR, Bressolle F, et al. In vitro and in vivo anti-tumoral activities of imidazo[1,2-a] quinoxaline, imidazo[1,5-a] quinoxaline, and pyrazolo[1,5-a] quinoxaline derivatives. Bioorg Med Chem 2008;16:6601-10.

30. Wood DC, Weber FS, Palmquist MA. Continued studies in the toxicology of dimethyl sulfoxide (DMSO). J Pharmacol Exp Ther 1971;177:520-7.

31. Khier S, Gattacceca F, El Messaoudi S, Lafaille F, Deleuze-Masquéfa C, Bompart J, et al. Metabolism and pharmacokinetics of EAPB0203 and EAPB0503, two imidazoquinoxaline compounds previously shown to have antitumoral activity on melanoma and T-lymphomas. Drug Metab Dispos 2010;38:1836-47.

32. He S, Cui Z, Wang X, Zhang H, Dai W, Zhang Q, et al. Cremophor-free intravenous self-microemulsions for teniposide: Safety, antitumor activity in vitro and in vivo. Int J Pharm 2015;495:144-53.

33. Lollo G, Rivera-Rodriguez GR, Bejaud J, Montier T, Passirani C, Benoit JP, et al. Polyglutamic acid-PEG nanocapsules as long circulating carriers for the delivery of docetaxel. Eur J Pharm Biopharm 2014;87:47-54.

34. Heurtault B, Saulnier P, Pech B, Venier-Julienne MC, Proust JE, Phan-Tan-Luu R, et al. The influence of lipid nanocapsule composition on their size distribution. Eur J Pharm Sci 2003;18:55-61.

35. Q3C (R6) Step 5 - Impurities: Guideline for Residual Solvents. Available from: http://www.ema.europa.eu/docs/en_GB/document_library/ Scientific_guideline/2011/03/WC500104258.pdf. [Last accessed on 2017 May 15]. 